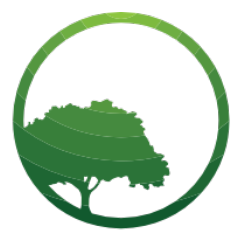

Business \& Social Science IJRBS

\section{Research in Business and Social Science}

IJRBS Vol 8 No 4, ISSN: 2147-4478

Contents available at www.ssbfnet.com/ojs

\title{
How Transformational Leadership Fuels Employee's Creative Performance Behaviors in the Workplace?
}

\section{Bruce Gashema}

Corresponding Author: School of Economics and Business Studies, Kigali Independent UniversityULK,Kigali, Rwanda Phone Number:+250788423061

ORCID ID: 0000-0003-4004-7463

\begin{abstract}
Supervisory transformational leadership behavior is attracting a widespread interest due to its fundamental quality that spurs subordinate confidence and optimism in the workplace. Although, despite the mounting evidence that links transformational leadership to different organizational and individual innovative outcomes, it is not yet been documented whether transformational leadership (TFL) can strengthen employee's creative performance behavior in the workplace. Recently, Successful entrepreneurs thrive under competitive pressures in today's high customer sensitivity to quality and innovative services. Hence, it's now clear that workplace creativity would be a potential solution for driving business success today. Although, the vital role of supervisory transformational leadership behavior in enhancing creative performance behavior of employees has not been dealt with in depth. However, the present paper aims to validate the potential and possible relationship between supervisory transformational leadership style and employee's creative performance behavior in the workplace. To prove or disprove the assumptions underlined in this study, a cross-sectional research design, was conducted using data from 14 commercial banks operating in Rwanda (412 of total respondents). A variety of methods and tools were employed to examine the relationship between the variables hypothesized in this study. We conducted CFA in SEM-Amos, mean and standard deviation using SPSS and also Hayes macro process to measure the possible effect of each variable in this model. The overall results support our hypothesized model. In this regard, we believe that we have obtained comprehensive results proving and validating the usefulness of our hypothetical model.
\end{abstract}

Key words: Creative Performance Behavior, Transformational Leadership, Creative Efficacy Beliefs, Climate for Creativity

JEL classification: $M 100, M 1, M 190$

Submitted: 05.06.2019 - Accepted: 21.06.2019

\section{Introduction}

TFL and its impact on employees' positive organizational behaviors have received much attention in management literature. Considering the recent review of the literature on TFL theory (TFL) (Jung, Bass, \& Sosik, 1995;Bass, Avolio, Jung, \& Berson, 2003;Bass, 1990), TFL behavior is widely considered to be the most important in driving employees positive behaviors in the workplace (Gashema \& Gao, 2018). In this view, Bass (2000), asserted that transformational leaders move followers beyond their own self-interests for 
the sake of organizational interests. In the same vein, Aurelija Stelmokiene \& Aukse Endriulaitiene, (2015) added that Transformational leaders engage their subordinates in extra-efforts behaviors. Recently, there has been a rapid rise in the use of TFL theory to explain the relationship between leadership style and positive employees' outcomes due to its potential to influence employees' attitudes see Yammarino \& Bass, (1990);Afsar \& Bin Saeed, (2014); Fernando, \& Caputi, (2010);Kang, Solomon, \& Choi, (2015). In another hand, today's business leaders are dealing with complex competitive concerns.

Today's business environment makes it especially difficult. New competitive advantage needs to be generated. Within this in mind, in today's fast-paced domestic and global markets, creative performance behavior set to become a vital factor in meeting customer needs and expectations. Although ,as mentioned by several authors, creativity plays a vital role in the long-term survival of organizations (Darvishmotevali, Altinay, \& Vita, 2018). Creativity performance which refers to the positive attitude toward performing the creative task (Cooper, Clasen, Jalonen, Butler, \& Cooper, 2006) would be an alternative solution for business needs to create a delightful customer. In consistent with Simmons \& Sower, (2014), employee's creativity often provides a starting point for organizational innovation. In the same view, Thundiyil, Chiaburu, $\mathrm{Li}, \&$ Wagner, (2016) consider creativity as potential and useful drivers of employee and organizational innovation. Although, within the context of these arguments from the literature, it's now clear that creativity would be a potential solution for driving business success today. Successful entrepreneurs thrive under competitive pressures, in this regard, (Karatepe, (2016) mentioned that employees creative performance lead to the role and extra-role performances which foster organizational competitiveness.

Drawing from transformational leadership theory (TFL) and also Considering different arguments from the previous studies, we believe that the fundamental characteristics of transformational leadership would be a solution for advancing creative performance behavior in the workplace. Although this approach is interesting, it is not yet known whether such leadership behaviors invigorate employee's creative performance behaviors in the workplace. Several authors have attempted to link transformational leadership with different organizational outcomes. For examples, CEO with TFL behavior and firm performance (Peterson, Walumbwa, Byron, \& Myrowitz, 2009), CEO TFL and new product development process (Sattayaraksa \& Boon-itt, 2016), TFL and organizational culture (Sarros, Cooper, \& Santora, 2008), CEO TFL and managerial innovation behavior (Gashema \& Gao, 2018). Other studies linked transformational leadership with different individual outcomes. For instance, TFL and employees innovative behavior (Afsar et al., 2014;Kang et al., 2015), creativity (Jaiswal \& Dhar, 2015;Khalili, 2016), TFL and employee work engagement (Raja, 2012). However, one of the main issues in our knowledge of transformational leadership theory is a lack of profound analysis of the TFL's potential to promote employee's creative performance behaviors in the workplace. Our knowledge of the relationship between TFL and employee's behavioral performance is largely based on very limited documentation. Recent studies of TFL theory generated its considerable interest in shaping followers attitudes (Bass et al., 2003;Bass \& Steidlmeier, 1999;Jung et al., 1995) and move the followers to extra-role behaviors (Janssen, 2004;Janssen, 2000;Scott \& Bruce, 1994; de Jong \& Den Hartog, 2007). Although, the potential relationship between TFL and employee's creative performance behaviors appear to be not well grounded and have not been dealt with in depth. Although, in light of recent literature on TFL, the present paper aims to validate the relationship between TFL and creative performance behaviors of subordinates. This paper takes a new look at the possible influence of TFL qualities on employee's positive organizational behaviors in the workplace. To pinpoint the mechanism in which transformational leaders influence employee's creative performance behaviors in the workplace, the new model developed in this study present employees creative Efficacy Beliefs in mediating the relationship between TFL and employee's creative performance behaviors. In the study, we have also introduced a climate for creativity to moderate the relationship between TFL and employee's creative performance behaviors. Within the framework of these variables, we believe that we have designed an innovative solution to employees' resistance to change in the workplace which broaden current knowledge of TFL theory in relation to employee's performance.

Henceforth, our new model developed in this study which is fully compliant with transformational leadership theory and bears a close resemblance to prior studies in the literature, present three noteworthy contributions in the management literature. First, a recent review of the literature on employee's creative performance have not been dealt with in depth and largely based on very limited studies. Many attempts have been made 
to examine the importance of creative performance in organizations but the potential effect of leadership style in strengthening creative performance behaviors remains unclear. However, there is still a need more studies on how leaders fuel such important behavior in the workplace. The aim of the research was thus to examine the possible influence TFL behavior to employee's creative performance behavior in the workplace. Second, an increasing number of studies mentioned creative efficacy as an engine for different employees' innovative outcomes. For examples, creative efficacy leads to work engagement (Chen \& Chen, 2016), innovative activities (Slåtten, 2014), innovative behavior (Hou \& Fan, 2011). However, introducing the mediating role of creative efficacy beliefs in the relationship between TFL and employee's creative performance behaviors shed new light on the possible and positive effect of supervisory leadership and subordinates' positive organizational behaviors. Third, several authors have attempted to examine the climate for creativity in relation to different innovation outcomes. Hence, this model that introduces climate for creativity to moderate the relationship between TFL and employee's creative performance behaviors underlined the importance of positive climate in organizational performance and widen our knowledge of TFL potentiality in organizational innovativeness.

\section{Literature Review}

\section{Theoretical Background}

The model developed in this study examine the effect of TFL behavior on employee's creative performance behavior in the workplace. Explaining this mechanism, this study employed creative Efficacy Beliefs of employees in mediating the relationship between TFL behavior and Employees creative performance behavior and also introduced climate for creativity to moderate this relationship. Underlying the rationale of this study, we used TFL theory (Bass et al., 2003;Bass, 2000; Bass \& Steidlmeier, 1999) to explain the relationship between variables hypothesized in this study.

\section{The Context of Transformational Leadership Theory}

James MacGregor Burns, an American historian, and political scientist was the first to introduce the concept of TFL in 1978. According to Burns, the transformational leader raises employees morale and self-motivation in the workplace (Jung et al., 1995). Later in 1985, Bernard Bass, an American scholar in the fields of leadership studies and organizational behavior expanded upon Burns' original ideas to develop what is today referred to as Bass' TFL (Bass, 1990;Bass \& Steidlmeier, 1999;Bass et al., 2003). Underlying the psychological mechanism that justifies and describes transformational and transactional leadership (Bass \& Avolio, 1990). According to Bass' TFL theory (TFL), transformational leaders move employees beyond their self-interest for the sake of the organizations (Bass, 2000). Bass et al., (2003) mentioned the main qualities of a transformational leader namely: "idealized influence (charisma), inspiration, intellectual stimulation, or individualized consideration". Janssen, (2000) explained how such special behavior of TFL engage followers towards extra-role behavior in the workplace. Drawing from TFL theory, several authors attempted to examine its relationship with different organizational and employees performance using different mechanisms, such as Jung, Chow, \& Wu, (2003) examined the relationship between TFL and organizational innovation, Slåtten \& Mehmetoglu, (2015);Choi, Kim, Ullah, \& Kang, (2016);Afsar et al., (2014);Kang et al., (2015) TFL and innovation behavior, TFL and firm performance (Peterson et al., 2009). However, in consistent with these arguments from the literature, we believe that supervisors with TFL behaviors value creativity and raise employee's efficacy in creativity which in turn lead to creative performance behavior.

\section{Transformational Leadership Behavior, Creative Efficacy Beliefs and Employee's Creative Performance Behaviors}

TFL is among the most widely studied constructs (Bass \& Steidlmeier, 1999; Jung et al., 1995) and attracting considerable widespread interest due to its fundamental qualities (Bass \& Avolio, 1990;Bass, 2000) that broadening and elevating followers' confidence to perform beyond their expectations (Kang et al., 2015). For examples, TFL has been associated with different employee positive behaviors, such as innovation performance (Sattayaraksa \& Boon-itt, 2016; Zuraik \& Kelly, 2018), innovation behavior (Afsar et al., 2014), work engagement (Fernando \& Caputi, 2012), creativity (Khalili, 2016),employee's entrepreneurial behavior (Afsar, Badir, Saeed, \& Hafeez, 2016),followers 'attitudes (Castro, Mar, Periñan, \& Casillas, 2008), 
knowledge-exchange behaviors (Castro et al., 2008). Although, within the framework of these important qualities that shape employees' attitudes, TFL is likely to become an important factor of creative Efficacy Beliefs and employee creative performance. In consistent with Bass, (2000);Jung et al., (1995);Bass et al., (2003), We believe that the four main components of TFL (Bass, 2000) play a central role in building Efficacy Beliefs and employee creative performance in the workplace.

\section{Four Dimensions of Bass' TFL Vs. Efficacy Beliefs and Employee Creative Performance}

\section{Leader's Idealized İnfluence vs. Efficacy Beliefs and Employee Creative Performance}

A leader with idealized influence behavior develops a sense of vision and mission among the followers (Yammarino \& Bass, 1990), such leader gain trust and respect from the followers (Jung et al., 1995). Bass \& Steidlmeier, (1999) added that an idealized influence leader envisages future success and set a high standard for achievement. Again high respect and trust which make such leader a role model for the followers (Bass et al., 2003). A charismatic or an idealized influence leader behavior also express followers beliefs and address their needs (Aggarwal \& Krishnan, 2015). According to Jung et al., (2003) a charismatic leader develops and support followers' self-esteem, self-confidence and self-efficacy. As mentioned by (Waldman, Siegel, \& Javidan, 2006), an idealized leader develop a vision among followers basing on humanistic values and justice, this special behavior makes subordinates feel valued and empowered. As a response, we believe that they will develop a sense of efficacy in creativity and creative performance behavior in the workplace since they are supported and empowered.

\section{Leaders Inspirational Motivation vs. Efficacy Beliefs and Employee Creative Performance}

A leader with inspirational motivation behavior inspires and motivate followers to visualize attractive future states (Jung et al., 1995), communicate high expectations to the followers and encourage their efforts (Bass et al., 2003). A leader with such behavior also energizes the follower's optimism and enthusiasm (Bass, 1990). In this regard, we believe that employees under such leadership develop self- efficacy beliefs and would display more creative performance behaviors. In consistent with Bass \& Steidlmeier, (1999), such leader boosts employees intrinsic enthusiasm and confidence to achieve high performance. In the same vein, Bass, (2000) added that an inspirational leader provokes the follower's optimism and open to innovativeness. However, with this in mind, we believe that such leader vitalizes and advance employee's efficacy beliefs in creativity and feed creative performance behaviors of employees.

\section{Leaders Intellectual Stimulation vs. Efficacy Beliefs and Employee Creative Performance}

A leader with intellectual stimulation behavior promotes intelligence, rationality, determination, and spirit of problem-solving (Jung et al., 1995;Yammarino \& Bass, 1990). In this regard, we believe that employees under such leadership behavior would develop self-confidence and self- efficacy belief to create a novel in the workplace. In the same view, Leaders with intellectual stimulation behaviors inspire and strengthen followers enthusiasm and energies to have a new look at old methods and solve the problems in their own ways (Bass \& Steidlmeier, 1999;Bass, 2000). Although, we hope that such specific behavior of a transformational leadership fuel creative performance behaviors of employees in the workplace since such leader promote followers talents and brilliance (Carless, Wearing, \& Mann, 2000;Bass \& Steidlmeier, 1999), build capability of analyzing and understanding among the followers (Bass, 1990;Bass, 2000).

\section{Individualized Consideration vs. Efficacy Beliefs and Employee Creative Performance}

According to Jung et al., (1995); Yammarino \& Bass, (1990), a leader with individualized Consideration treat each employee individually, the leader gives personal attention, coaches, advises. Although, an employee under such leadership feel valued in the organization and develop self- efficacy, and dedication to work. Such a leader also encourages employees to engage in a greater level of responsibility (Bass \& Steidlmeier, 1999). We believe that a leader with individualized Consideration fuels employees Efficacy Beliefs since such leader foster individual development (Bass, 2000) and create new learning opportunities Bass et al., 2003). 
Bruce Gashema / International Journal of Research in Business and Social Science,

Vol 8 No 4, 2019 ISSN: 2147-4486

\section{Creative Efficacy Beliefs and Employee's Creative Performance Behaviors}

The concept of creative self-efficacy has its roots in Bandura's social cognitive theory. Bandura defined the concept of self-efficacy as people's beliefs about their capabilities to produce designated levels of performance. In the same view, Chen \& Chen, (2016) uses this term to refer to people's beliefs about their competences to successfully achieve goals. In regard, it stands to the reason that if one has such a belief would display more creative behaviors in the workplace. According to Puente-díaz, (2016), employees selfefficacy can predict creative performance. Beghetto, (2010) introduced creative efficacy as a specific behavior that produces creative outcomes. In this view, we believe that employee equipped with creative efficacy belief take creative risks and engage frequently in creative activities. Using three components of selfefficacy namely: Judgement, dynamics and mobilization, Slåtten, (2014) explained creative self-efficacy as one's Capabilities to mobilize the motivation, cognitive resources, and action needed to meet given job demands. In another hand, it is well known that creativity is prioritized under transformational leadership. However, we can predict the creative performance behavior of employees with creative self- efficacy belief since it is supported by the leaders. Several authors have attempted to link creative self-efficacy quality with different employees' outcomes, such as Creative Self-Efficacy and employee's innovative behavior (Hou \& Fan, 2011), Employee Creativity (Mittal \& Dhar, 2015), Creative Work Involvement (Bang \& Reio, 2017),work engagement (Chen \& Chen, 2016), innovative activities (Slåtten, 2014). Although, since creative efficacy is productive in other individual performance outcomes, it stands to reason that employees with creative efficacy are likely to exhibit more creative performance behavior in the workplace.

\section{Climate for Creativity and Employee's Creative Performance Behaviors}

Climate for creativity construct as a psychological atmosphere and motivation, set to become a vital factor in driving employees' creative behaviors in the workplace. Under the climate for creativity, creativity is encouraged, autonomy and freedom are promoted, Resources are mobilized and leaders are willing to facilitate interventions (Yeh-Yun Lin \& Feng-Chuan Liu, 2012). According to Yström, Aspenberg, \& Kumlin, (2015) climate for creativity play a central role in motivating the workforce to think creatively. Creativity supporting climate consist of policies, practices, procedures, routines, and rewards that support creative ideas (Heffernan, Harney, Cafferkey, \& Dundon, 2016). As mentioned by Mafabi, Munene, Ahiauzu, Mafabi, \& Munene,(2015), the climate for creativity mainly characterized by recognition and reward for creative work and fair evaluation of creative work. Within this in mind, Climate for creativity can be effective predictors of creative performance. These assumptions are consistent with the study by Koustab Ghosh, (2015),described creativity climate as workplace positive atmosphere characterized by the openness of communication, care for employees, enjoyable ambiance, emotional and functional support. However, seeing that climate for creativity is such an important in creativity outcomes, we assume that creativity climate affects the relationship between transformation leaders and employees' creative behaviors in the workplace.

\section{Hypotheses Development}

\section{Transformational leadership and Creative performance behaviors}

Due to its fundamental characteristics, TFL behavior set to become a vital factor in developing the follower's confidence and optimism in the workplace (Jung et al., 1995;Bass et al., 2003). Researchers have always seen transformational leadership behavior as the main engine for the employee's innovative outcomes. According to Bass \& Steidlmeier, (1999) Leaders are transformational when they elevate followers selfactualization, followers higher moral maturity and increase the follower's confidence and needs to achieve a high level of task performance. Transformational leaders use their specific characters to meet the emotional needs of each employee and intellectually stimulate employees to generate their awareness and commitment to the organizational mission (Bass, 1990). Employees' behavior partly depends on their perception of supervisory leadership (Stelmokiene \& Endriulaitiene, 2015). In this context, employees are likely to exhibit more creative behavior under the leadership that is dedicated to transformation. For More recent evidence, Transformational leaders provide individualized support to staff and encourage their individual development (Carless et al., 2000), they facilitate their followers to learn and implement new skills (Bass et al., 2003). 
Although, it is within this in mind that we tested the possible effect of supervisory TFL behavior on employees' creative behaviors in the workplace. This relationship is fully compliant with transformational leadership theory, more specifically its four dimensions, see Waldman et al., (2006);Bass, (2000);Bass \& Steidlmeier, (1999). As others have highlighted, with inspirational behavior of TFL, mentoring and coaching practice is prioritized (Bass, 2000), intellectual stimulation of TFL arouse followers problem-solving skills (Yammarino \& Bass, 1990), individualized consideration of TFL build employees confidence and optimism while inspirational motivation behavior of TFL broaden the followers needs and willingness to perform at a high level of standard. We thus propose the following hypothesis:

H1: Supervisory TFL behavior positively affects an employee's creative performance behavior in the workplace.

\section{Transformational Leadership and Employees Creative Efficacy Beliefs}

The term transformation is generally understood to mean the change. Several authors have attempted to define transformational leadership behavior as a supervisory behavior dedicated to change in the organization. According to Bass \& Avolio, (1990), TFL is required if firms are to overcome today business environment challenges. Basing on the fundamental qualities of TFL such as promoting individual development and new learning opportunities (Jung et al., 1995), prompting followers confidence and enthusiasm (Bass et al., 2003), arousing and supporting followers creativity and innovativeness (Bass, 2000), we can predict employees creative Efficacy Beliefs when under supervisory TFL. As mentioned in TFL theory (TFL) (Yammarino \& Bass, 1990), Transformational leaders use proactive approach to the mistakes, acknowledge the mistakes, attempt to correct and learn from the mistakes (Bass \& Steidlmeier, 1999;Bass, 1990 ) and such practices energize employees confidence to overcome fear and embrace creativity in the workplace. When failures occur in the workplace, transformational leaders proactively make a diagnosis on the problems and try to turn them into learning experiences rather than criticizing employees or punishing them (Bass \& Avolio, 1990). Although, such supervisory behavior gives employees a sense of creative efficacy, especially when they face creativity challenges in the workplace. Employees creative efficacy can be aroused also by the fact that transformational leader facilitates employees in formulating and implementing their innovation plans and try to link them with organizational innovation strategies (Sattayaraksa \& Boon-itt, 2016). A leader who exhibits TFL vitalizes and spur employee's willingness for exploration, fostering a learning climate and promoting employees risk-taking in the workplace (Zuraik \& Kelly, 2018). Hence, drawing from TFL theory, this study takes a new look at how a supervisor with TFL behavior spurs employees creative Efficacy Beliefs of employees in the workplace. We thus propose the following hypothesis:

\section{H2: Supervisory TFL behavior builds and develops employees creative Efficacy Beliefs in the workplace}

\section{Employees Creative Efficacy Beliefs and Creative Performance Behaviors}

Self-Efficacy as a part of the social cognitive theory (Bandura, 1994) is recognized as being a highly accurate predictor of the degree of behavioral change (Bandura, 1989). Creative Self-Efficacy is believed to become a central factor for employee's Creative performance behavior. In the study by Chen \& Chen, (2016), selfefficacy is defined as an individual's belief in their innate ability to achieve goals and proven to play a pivotal role in promoting employee work engagement. Bandura, (1994), defined efficacy Beliefs which produce diverse effects through four major processes namely: cognitive, motivational, affective and selection processes as people's beliefs about their capabilities to produce effects and designated levels of performance. In line with Beghetto, (2010), we consider employees creative performance behaviors as antecedents of their self-efficacy. In the same view, Puente-díaz, (2016) added that creative self-efficacy arouse employees creative mindset. Although, Employees creative Efficacy Beliefs set to become a vital factor in predicting creative performance behaviors in the workplace. Our assumptions are also consistent with several studies in the literature, for examples, Slåtten,(2014) found a positive effect of creative selfefficacy on employees innovative activities. Hou \& Fan, (2011) found a positive relationship between creative self-efficacy, optimism, and innovative behavior. In the same vein, self-efficacy has been widely investigated in the study by Mittal \& Dhar, (2015) and found to be a potential factor of employees creativity. In the literature, a growing body of literature has examined the potential of self-efficacy and proved it as an engine 
of employee's behavioral change. Although, within this in mind, we consider Self- efficacy as an individual's self-ability (Puente-díaz, 2016) to achieve creative results (Bandura, 1994) and likely to become an important driver of employees creative performance in the workplace. We thus propose the following hypothesis:

H3: Employees creative Efficacy Beliefs spur Creative performance behaviors in the workplace

\section{Climate for Creativity and Creative Performance Behaviors}

Workplace climate that supports creativity is widely considered to be the most important factor of creative behaviors. In the literature, Construct of creativity climate tends to be used to refer to an environmental attribute that shape expectations about outcomes, requirements, contingencies, and interactions in the workplace (Hunter et al., 2007). In line with Social information-processing theory, employees seek to understand their work environments by observing social interactions and atmosphere surrounding them (Sung, Du, \& Choi, 2018). Although, it is believed that climate for creativity spur employees creative performance behaviors in the workplace. According to Yström et al., (2015), the climate for creativity improve the ability to implement complex work designs in the workplace. In the same context, Esch, Wei, \& Chiang, (2018) added that creativity climate enhances employees' abilities, motivation and behavior desired in the workplace. In this regard, assumptions proposing creativity climate to moderate the relationship between supervisory TFL behavior and employee's creative performance behavior seem to be realistic. A growing body of literature has examined the potential effect of climate for creativity on different organizational and individual outcomes. For examples, in the study by Mafabi et al., (2015) its impact on organizational resilience has been proven, climate for creativity also has been linked to innovation (Yeh-Yun Lin \& Feng-Chuan Liu, 2012) and job performance (Sung et al., 2018). However, in our view, these theoretical arguments from the literature emphasize the validity of our model. This new mechanism developed in this model represents a viable relationship between supervisory leadership and subordinate attitudes and validates the usefulness of environmental positive atmosphere in predicting employees behavioral change. Thus, we propose the following hypothesis:

H4: Climate for creativity moderate the relationship between supervisory TFL behavior and employee creative performance behavior, such that, this relationship is more positive with high than with low perception of climate for creativity in the workplace

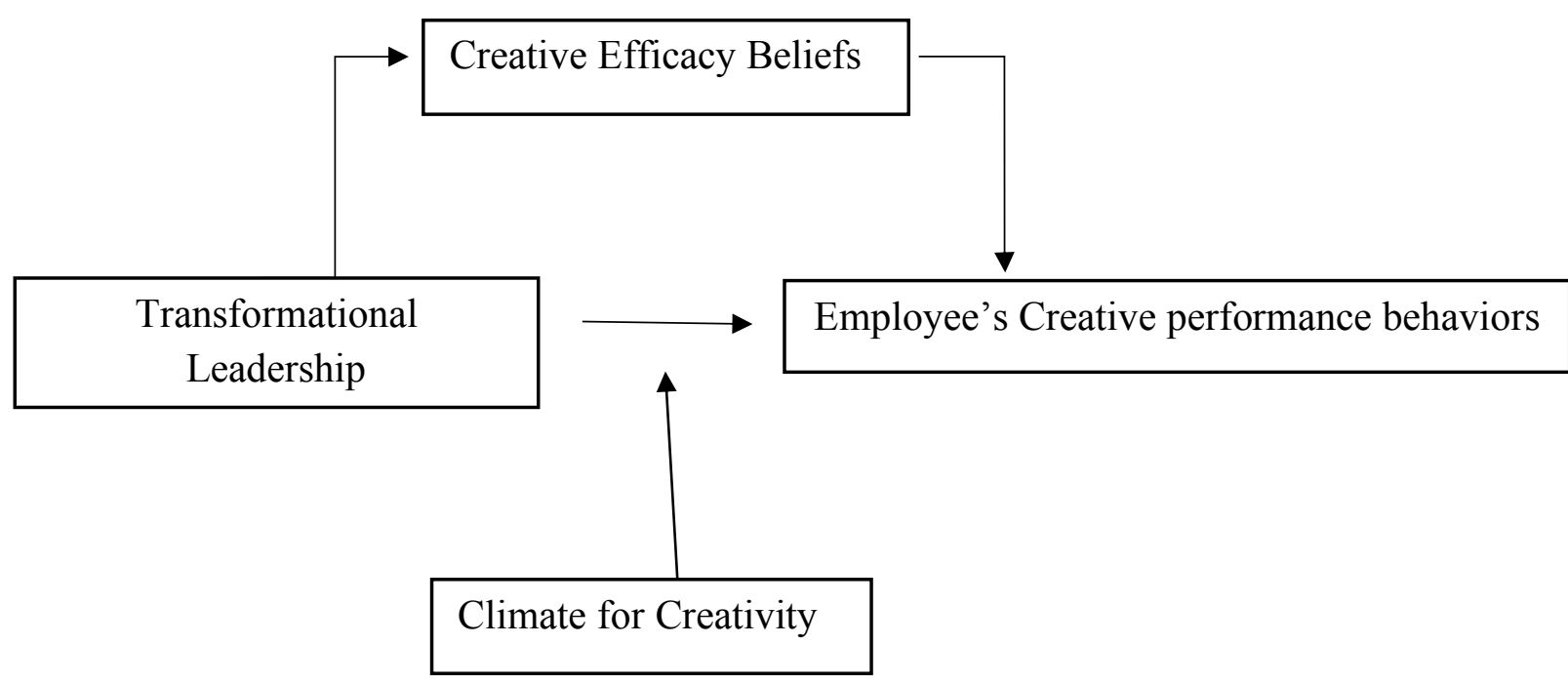

Figure 1: Conceptual Model of the study 


\section{Research and Methodology}

This section introduces the techniques and procedures used in collecting and analyzing data used in this study which allows the author to test the validity and reliability of measurement instruments used in testing hypothesis developed in this study. The section present research design, the population of the study, sample, and procedure.

\section{Study Design, Target Population, and Procedure of Data Collection}

In this study, we employed a cross-sectional research design to test the relationship between the variables hypothesized. The target population of this study comprises of 4688 employees and operational level managers of commercial banks operating in Rwanda. Through proportionated stratified sampling techniques, 462 respondents were selected from 14 commercial banks based in Kigali. In this regard, 462 survey questionnaires were distributed to the respondents who voluntarily accepted to participate in this study. To avoid and minimize the possible common method bias, we distributed survey questionnaires in two phases. In phase one, 462 copies of questionnaire rating supervisory leadership behavior, creativity climate were distributed. 30 days later, another round of 462 copies of questionnaire rating creative performance behavior and creative efficacy beliefs were distributed to the same sample. After matching time-lag of data collection, dropping some biased, uncompleted and untrustworthy answers from the questionnaire, 412 copies of survey questionnaire were found completed which count $89 \%$ of response rate.

\section{Measurement}

To examine the possible relationship between variables hypothesized in this study, we used multi-items scales adopted from prior studies in the literature. Apart from the general identification of respondents, all items were measured using a seven-point Likert-type scale where (1) strongly disagree to (7) strongly agree. The Control variables. In this study, we controlled respondent age, gender, education and organizational tenure to rule out its alternative effects on the outcome variable. According to Thundiyil et al., (2016), Jun Song, Jianlin Wu \& Jibao Gu, (2017), these variable are associated with employees self-efficacy and creative behavior.

Table 1: Summary of variables and measurement

\begin{tabular}{llll}
\hline Variables & $\begin{array}{l}\text { Variable } \\
\text { category }\end{array}$ & $\begin{array}{l}\text { Number } \\
\text { of items }\end{array}$ & Measurement sources \\
\hline Transformational leadership & IV & 7 & GTL Carless et al., (2000) \\
Creative performance behavior & DV & 6 & Karatepe, (2016) \\
Creativity climate & Moderator & 5 & Hassi, (2019) \\
Creative self-efficacy & Mediator & 3 & Chen, (2016); Slåtten, (2014) \\
\hline
\end{tabular}

\section{Common Method Variance}

The fact that the data used in this study were collected from the same respondents, the possibility of common method bias cannot be ignored. In this regard, two widely adopted methods namely Harman's one-factor and variance inflation factor (VIF) were tested using SPSS 24.

The results revealed that there was no common bias in this study. VIF test suggests all constructs are below 3.3 recommended (Kock \& Lynn, 2012). In another hand, Harman's one-factor test revealed that the first factor explained is $31.6 \%$ which is below the threshold level of $50 \%$ recommended (Organ \& Kovovsky, 1989) see table 2. 
Bruce Gashema / International Journal of Research in Business and Social Science,

Vol 8 No 4, 2019 ISSN: 2147-4486

Table 2: Total Variance Explained

\begin{tabular}{|c|c|c|c|c|c|c|}
\hline Factor & Initial E & genvalues & Extra & on Sums & of Squared Loadin & \\
\hline$\%$ & Total & $\%$ of Variance & Cumulative \% & Total & $\%$ of Variance & Cumulative \\
\hline 1 & 1.730 & 43.239 & 43.239 & 1.268 & 31.694 & 31.694 \\
\hline 2 & .975 & 24.365 & 67.605 & & & \\
\hline 3 & .796 & 19.888 & 87.493 & & & \\
\hline 4 & .500 & 12.507 & 100.000 & & & \\
\hline
\end{tabular}

Extraction Method: Principal Axis Factoring.

\section{Reliability and Validity Testing}

To test the validity and reliability of the instruments used in this study, we used different approaches adopted in prior studies. In consistence with Khalili, (2016) to check whether all standardized factor loadings are at least above 0.4 , the test suggests all factor loadings are within an acceptable range (See Table 3 ). In this study, Cronbach was also tested. the results revealed that all constructs are above 0.6 recommended (Cronbach, 1951).

As recommended by Fornell \& Larcker, (1981), Average variance extracted (AVE) and Composite reliability $(C R)$ were also tested. The results suggest that all constructs are within the cut-off suggested (i.e. AVE $\geq 0.5$ and $C R \geq 0.6$ ) (Richard R Bagozzi \& Youjae $Y i, 1988$ ).

Table 3: Reliability and Validity

\begin{tabular}{lllll}
\hline Items & Factor loadings & Cronbach $\boldsymbol{\alpha}$ & AVE & CR \\
\hline TFL1 & 0.846 & & & \\
TFL2 & 0.708 & & & \\
TFL3 & 0.739 & & & \\
TFL4 & 0.666 & & & \\
TFL5 & 0.809 & 0.87 & 0.53 & 0.79 \\
TFL6 & 0.648 & & & \\
TFL7 & 0.657 & & & \\
CRP1 & 0.786 & & & \\
CRP2 & 0.821 & & & \\
CRP3 & 0.748 & 0.90 & 0.60 & \\
CRP4 & 0.819 & & & \\
CRP5 & 0.703 & & & \\
CRP6 & 0.767 & & & \\
CLC1 & 0.844 & & & \\
CLC2 & 0.694 & 0.86 & 0.55 & \\
CLC3 & 0.609 & & & \\
CLC4 & 0.707 & & & \\
CLC5 & 0.854 & 0.90 & 0.86 & \\
CSE1 & 0.890 & & & \\
CSE2 & 0.893 & 0.821 & & \\
CSE3 & 0.821 & & \\
\hline
\end{tabular}

TFL: Transformational leadership, CRP; Creative performance, CLC: Climate for creativity, CSE: Creative self-efficacy

\section{Findings}

As recommended by Anderson \& Gerbing, (1988),we conducted confirmatory factor analysis (CFA) in twostep modeling approaches namely : measurement model and structural model using Amos version 23. We have also used a bootstrapping technique developed by Hayes, (2009) to deeply examine the mediating and moderating effects in our model (Fairchild \& MacKinnon, 2009). In the first step for measurement model, we 
conducted CFA for each construct used in our study (i.e. Transformational leadership, creative efficacy beliefs, climate for creativity and creative performance behavior). We adopted two widely used indices namely; absolute fit indices and incremental fit indices (i.e. X2/df, RMSEA, CFI, TLI, SRMR) to evaluate the goodness of fit (Hu \& Bentler, 1998). We used X2/df as an alternative since $x 2$ is sensitive to sample size (Shah \& Goldstein, 2006). According to Hair, Black, Babin, \& Anderson, (2010), a value below 3.00 indicates a good fit of X2/df. For RMSEA and SRMR, Hu \& Bentler, (1998) recommended the value below 0.08 as a cut-off while CFI and TLI show a good fit if the value is equal or above 0.90 (Hair, Sarstedt, Ringle, \& Mena, 2012). However, the results of CFA for the measurement model indicate a good fit of all constructs tested (see table 4. In this regard, in line with below CFA test results, we can confirm the validity and reliability of measurement model in this study.

Table 4: CFA for the measurement model

\begin{tabular}{llllll}
\hline Constructs & X2/df & CFI & TLI & RMSEA & SRMR \\
\hline Transformational leadership & 2.205 & 0.99 & 0.98 & 0.05 & 0.02 \\
Creative efficacy & 0.03 & 1.00 & 1.00 & $<0.01$ & $<0.01$ \\
Climate for creativity & 1.56 & 0.99 & 0.98 & 0.03 & 0.01 \\
Creative performance behavior & 2.209 & 0.99 & 0.98 & 0.05 & 0.01 \\
\hline
\end{tabular}

In the second step (i.e. Structural path), we tested our baseline model to assess the possible relationships among variables that serve as predictors in one single and hypothetical model. According to Peterson et al., (2009), it is often recommended to compare the fit of a hypothetical model to alternative models to find which model fit in the data adequately. In this regard, in line with Hsu \& Chen, (2017), we tested CFA for other three alternative models and compared with our baseline model. For a good comparison, we considered (5) widely adopted fit indices (i.e. X2/df, TLI, CFI, RMSEA, and SRMR). Although, according to the CFA test, our baseline model shows adequate to fit in the data comparing with other alternative models tested (see table, $5)$.

Table 5: CFA results, Comparison of measurement models

\begin{tabular}{llllll}
\hline Models & $\mathbf{X}^{2}$ /df & TLI & CFI & RMSEA & SRMR \\
\hline Baseline model & 2.877 & 0.92 & 0.93 & 0.06 & 0.04 \\
3 factors model (a) & 4.215 & 0.88 & 0.89 & 0.08 & 0.05 \\
2 factors model (b) & 5.110 & 0.89 & 0.90 & 0.10 & 0.05 \\
1 factor model (c) & 13.343 & 0.46 & 0.54 & 0.17 & 0.15 \\
\hline \multicolumn{7}{l}{ Note: (a), we tested a combination of Transformational leadership, climate for creativity and creative performance. (b), } \\
we tested a combination of Transformational leadership and creative performance. (c), all constructs were merged.
\end{tabular}

\section{Hypotheses Testing}

Beside the CFA tests of our hypothetical model which indicated good fit in the data (i.e. $\mathrm{X} 2 / \mathrm{df}=2.877$, $\mathrm{TLI}=0.92, \mathrm{CFI}=0.93$, RMSEA=0.06, $\mathrm{SRMR}=0.04$ ), descriptive and inferential statistical tests (i.e. Correlations, mean and standard deviations) were also conducted to profoundly find out the possible relationship between hypothesized variables. As indicated in table 6 , the variables hypothesized in this study are significantly correlated with each other. For example, the result indicates a significant influence of transformational leadership on creative efficacy beliefs of employees $(r=0.183 ; p<0.01)$ and employees creative performance behavior $(r=0.366 ; p<0.01)$. Thus, hypothesis $1 \& 2$ are both supported. In the same view, the result also approves the influence of employee's efficacy beliefs on creative performance behavior $(r=0.208 ; p<0.01)$. Hence hypothesis 3 is supported. Finally, Pearson correlation test also shows a significant effect of climate for creativity on employee's creative performance behavior $(r=0.208 ; p<0.01)$. Hence, hypothesis 4 is also supported. 
Table 6:Descriptive Statistics and inter-correlations

\begin{tabular}{|c|c|c|c|c|c|c|c|c|c|c|c|c|}
\hline & & $\mathbf{M}$ & SD & 1 & 2 & 3 & 4 & 5 & 6 & 7 & 8 & 9 \\
\hline 1 & Age & 2.74 & 0.792 & 1 & & & & & & & & \\
\hline 2 & Gender & 1.57 & 0.495 & $.174^{* *}$ & 1 & & & & & & & \\
\hline 3 & Job level & 1.26 & 0.439 & $.735^{* *}$ & $.138^{* *}$ & 1 & & & & & & \\
\hline 4 & Tenure & 4.54 & 0.866 & $.156^{* *}$ & -0.020 & $.209^{* *}$ & 1 & & & & & \\
\hline 5 & Education & 5.25 & 0.572 & $.357^{* *}$ & $.139^{* *}$ & $.424^{\star *}$ & -0.016 & 1 & & & & \\
\hline 6 & TFL & 27.53 & 13.603 & $.161^{* *}$ & -0.033 & $.252^{* *}$ & $.236^{* *}$ & 0.068 & 1 & & & \\
\hline 7 & CRP & 27.1117 & 12.73928 & $.321^{* *}$ & $.199^{* *}$ & $.475^{* *}$ & -0.089 & $.219^{* *}$ & $.366^{* \star}$ & 1 & & \\
\hline 8 & CLC & 24.6675 & 10.42847 & 0.048 & 0.059 & $.151^{* *}$ & -0.083 & 0.015 & $.208^{* *}$ & $.430^{* *}$ & 1 & \\
\hline 9 & CSE & 15.0655 & 6.89604 & $.113^{*}$ & 0.043 & 0.037 & $-.122^{*}$ & $.157^{* *}$ & $.183^{* *}$ & $.208^{* *}$ & $.188^{* *}$ & 1 \\
\hline & $\begin{array}{l}\text { ** Correlati } \\
\text { * Correlatic }\end{array}$ & 9.8 & ie 0.05 । & 8 (1) & & & & & & & & \\
\hline
\end{tabular}

\section{Mediation effect analysis}

To analyze the possible effect of mediation in the model, we used bootstrapping technique developed by Hayes, (2009) know as Hayes process macro. This approach is widely adopted due to its adequacy in measuring moderation and mediation effect in structural model (Fairchild \& MacKinnon, 2009). Using 5000 resample in process macro, we examined the main three paths suggested by Mathieu \& Taylor, (2006) to determine whether mediation is significant or there is no mediation in the structural model. Below are the main paths tested

1. $X$ variable predict $Y$ variable (path $-C$ )

2. $X$ variable predict $M$ variable (path $-A$ )

3. $X$ variable \& $M$ variable together predict $Y$ variable

a. $M$ variable predict $Y$ variable (path- $B$ )

b. $\quad X$ variable no longer predict $Y$ variable or is lessened predicting $Y$ (path- $\left.C^{\prime}\right)$

Path Analysis of Transformational Leadership Behavior, Creative Efficacy Beliefs and Employee's Creative Performance Behaviors

1. $X$ variable predict $Y$ variable (path $-C$ )
a. $F(1,410)=63.4, p<0.01, R 2=.133$
b. $b=.3427, t(410)=7.9, p<0.01$

2. $X$ variable predict $M$ variable (path $-A)$
a. $F(1,410)=20.5, p<0.01, R 2=.0476$
b. $b=.1055, t(410)=16.9, p<0.01$

3. $\mathrm{X}$ variable \& $\mathrm{M}$ variable together predict $\mathrm{Y}$ variable

a. $F(2,409)=36, p<0.01, R 2=.1497$

b. $M$ variable predict $Y$ variable (path- $B$ )

i. $\quad b=.2492, t(409)=2.75, p<0.01$

c. $X$ variable no longer predict $Y$ variable or is lessened predicting $Y$ (path- $C^{\prime}$ )

i. $\quad b=.3165, t(409)=7.2327, p<0.01$ 
Bruce Gashema / International Journal of Research in Business and Social Science,

Vol 8 No 4, 2019 ISSN: 2147-4486

Table 7: Outcome variable / Creative performance behavior

\begin{tabular}{lllllll}
\hline $\mathbf{R}$ & $\mathbf{R}$-sq & MSE & F & DF1 & DF2 & P \\
\hline .3869 & .1497 & 138.6678 & 36.0059 & 2.0000 & 409.0000 & .0000
\end{tabular}

Model

\begin{tabular}{llllll}
\hline \multicolumn{1}{c}{ COEFF } & $\mathbf{S E}$ & $\mathbf{t}$ & $\mathbf{P}$ & $\mathbf{L L C l}$ & ULCl \\
\hline const.14.6620 & 1.7080 & 8.5843 & .0000 & 11.3044 & 18.0195 \\
TFL .3165 & .0438 & 7.2327 & .0000 & .2304 & .4025 \\
CSE .2492 & .0905 & 2.7533 & .0062 & .0713 & .4271 \\
\hline
\end{tabular}

As indicated in the path's analysis, the macro process results indicate the significance of all three paths. In path-A, transformational leadership behavior predicts creative efficacy beliefs of employees (i.e. $\beta=.1055, p$ $<0.01$ ). In path-B, employees creative efficacy beliefs predict creative performance behavior of employees (i.e. $\beta=.2492, p<0.01$ ). In path-C, transformational leadership behavior predicts employee's creative performance behaviors (i.e. $\beta=.3427, p<0.01$ ). In path- $C^{\prime}$, transformational leadership and creative efficacy beliefs together predict employee's creative performance behaviors, the results show significance mediation and also with no mediation (i.e. $\beta=.2492, p<0.01$ and $\beta=.3165, p<0.01$ ). According to Mathieu \& Taylor, (2006), since both mediation and no mediation are significant and also based on the fact that the introduction of mediation does not weaken the direct value of IV to DV, the partial mediation of creative efficacy beliefs in the relationship between transformational leadership and employees creative performance behavior is accepted. Additionally, the fact that zero does not lies in between $95 \%$ confidence intervals, (see table 7) the indirect effect of transformational on creative performance behavior of employees can also be confirmed (Hayes, 2009; Fairchild \& MacKinnon, 2009).

\section{Moderation Analysis}

To assess more specifically whether climate for creativity affects the relationship between transformational leadership and employee's creative performance behavior, we conducted a multiple regression analysis using Hayes macro process in SPSS. According to Fairchild \& MacKinnon, (2009), this approach provides vital results in analysing the potential moderation effect in the model. The results indicate that the climate for creativity moderates the relationship between transformational leadership behavior and employee's creative performance behavior in the workplace. (i.e. $\mathrm{R}=.5238$, R2=.2744, $\mathrm{MSE}=118.6, \mathrm{~F}=51.4, \mathrm{p}<0.01$ ). As mentioned by (Hayes, 2009), the fact that bias-corrected bootstrap confidence intervals (Cl) do not contain zero (see table 8), we can confirm the significance of moderating effect in the model.

Table 8: Model summary outcomes/Employee creative performance behavior

\begin{tabular}{|c|c|c|c|c|c|c|}
\hline \multicolumn{2}{|c|}{ COEFF. } & \multirow[t]{2}{*}{ SE } & \multicolumn{2}{|c|}{ t-value } & \multicolumn{2}{|c|}{$\mathrm{ULCl}$} \\
\hline Constant & $27.3817^{* * *}$ & & .5496 & 49.8223 & 26.3 & 28.46 \\
\hline TFL & $.2719^{\star * *}$ & & .0404 & 6.7341 & .1926 & .3513 \\
\hline CLC & $.4147^{\star * *}$ & & .0552 & 7.5096 & .3061 & .5233 \\
\hline Int_1 & $-.0092^{* *}$ & & .0040 & -2.2731 & -.0171 & -.0012 \\
\hline
\end{tabular}

${ }^{* * *}=p<0.001$

${ }^{* *}=p<0.005$ 
Table 9: Conditional effects of the focal predictor at values of the moderator

\begin{tabular}{|c|c|c|c|c|c|c|}
\hline$\overline{C L C}$ & EFFECT & SE & t-value & LLCl & ULCI & \\
\hline$-13.6675^{\star \star *}$ & .3972 & .0688 & 5.7723 & .2619 & .5325 & \\
\hline $4.3325^{* * *}$ & .2322 & .0438 & 5.3070 & .1462 & .3182 & $10.3325^{\star *}$ \\
\hline .1772 & .0576 & 3.0774 & .0640 & .2904 & & \\
\hline
\end{tabular}

Note: $\mathrm{CLC}=$ Climate for creativity

In line with Mathieu \& Taylor, (2006) and as recommended by Hayes, (2009), we conducted a plot indicating the conditions under which a given predictor is related to outcome. Although, as indicated in the plot of Hayes process macro v.3 (figure 2), climate for creativity predict employee's creative performance behavior in the workplace, in the way that employees display more creative performance behaviors with high than with low perception of climate for creativity in the workplace. Hence within this in mind, the moderation effect of climate for creativity in the relationship between transformational leadership and employee's creative performance behavior is confirmed.

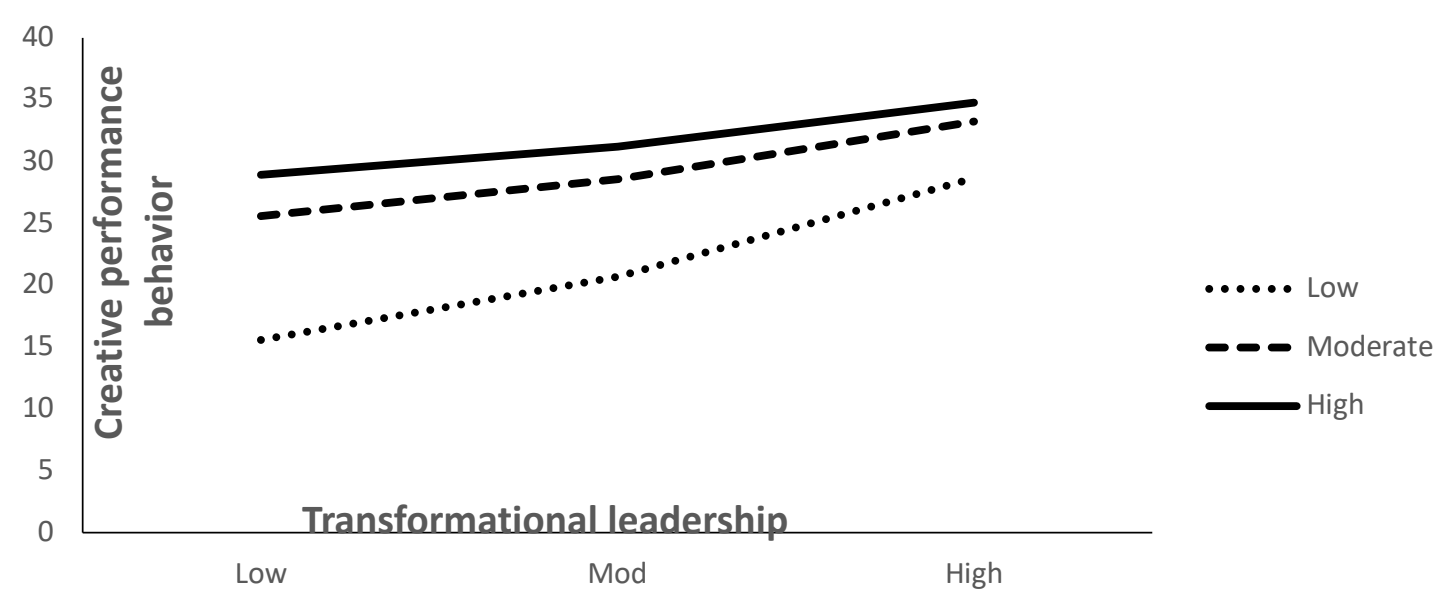

Figure 2: A plot of the moderation effect

\section{Discussion}

The new model developed in this study presents a viable mechanism in which supervisory leadership behavior influence employee's organizational positive behavior in the workplace. Interestingly, the tests employed in this paper revealed a significant and positive relationship between the variables hypothesized in this study. For example, in this study, we tested the possible influence of TFL behavior to subordinate's creative performance behavior $(\mathrm{H} 1)$ and self-efficacy beliefs $(\mathrm{H} 2)$. The results suggest a positive effect of TFL behavior on both creative performance behavior of employees $(r=0.366 ; p<0.01)$ and creative efficacy beliefs of employees $(r=0.183 ; p<0.01)$. Although, this result has further strengthened our confidence in our model which advance the current knowledge of transformational leadership qualities in driving organizational performance. In the same vein, we measured the effect of employee's efficacy beliefs on creative performance behavior $(\mathrm{H} 3)$ and the results support this effect $(r=0.208 ; p<0.01)$. Finally, these statistical tests show a positive effect of climate for creativity on employee's creative performance behavior $(r=0.208$; $\mathrm{p}<0.01$ ). However, in our view, the result emphasizes the validity of our model. Additionally, further tests carried out using different approaches such as CFA tests (see table 5) and Hayes macro process (see pathsanalysis on pp.14) also provides additional support for our hypothesized model. 
In this regard, drawing from transformational leadership theory, these different measurements validate the usefulness of transformational leadership theory in managerial practices and provide vital evidence for managing employees' behaviors in the workplace. Within this in mind, our findings which appear to be well supported by TFL theory confirmed substantially our hypothetical model. Creativity has always been at the heart of business (Khalili, 2016;Li, Zhao, \& Begley, 2015). Although, we believe that our new mechanism could probably be usefully employed in managing workplace creativity issues since most managers have to deal with poor employee performance for the sake of organizational goals. According to several studies in the literature, creativity fuels big ideas and challenges employees' new way of thinking (Slåtten \& Mehmetoglu, 2015 ;Hunter et al., 2007). Although, in our opinion, the results of this study point to the likelihood of enhancing employee's creativity behavior in the workplace. This mechanism would lead management to encourage employees at all levels to contribute novel ideas for improving current business operations. This new model fuels Employees feeling that their creative ideas contribute to the ways of growing the business.

\section{Managerial implications}

Today, organizations operate in a highly competitive and global environment that makes creativity very crucial. In this regard, the strength of this study lies on its specific focus on the effect of supervisory leadership behavior on the subordinate's creative behavior in the workplace. According to TFL theory (Bass, 2000), through the strength of their vision and personality, transformational leaders are able to influence followers to change expectations, perceptions, and motivations to work towards common goals (Bass \& Steidlmeier, 1999;Jung et al., 1995). TFL behavior contains an exceptional quality of influence that moves followers to accomplish more than what is generally expected of them (Yammarino \& Bass, 1990; Bass, 1990). Within this view in mind, this study has gone some way towards enhancing our understanding of supervisory TFL behavior that gives rise to creativity performance in the workplace. Having creative employees in the business organizations would be the driving force behind the organizational success in innovativeness (Sattayaraksa \& Boon-itt, 2016;Khalili, 2016). However, this study so far has been very promising and might be useful for overcoming innovation obstacles and Creativity Challenges in the workplace. Additionally, Creative employees tend to require appropriate consideration and attention (Khalili,2016;Gashema \& Gao, 2018). Although, we are confident that our study may improve knowledge on how to achieve extraordinary outcomes through TFL behaviour in the workplace.

\section{Conclusions}

Transformational leadership theory guarantees that transformational leaders strengthen subordinate's optimism and confidence (Bass \& Steidlmeier, 1999; Afsar et al., 2014) and it can be generalized to employees creativity (Khalili, 2016). Although, insight has been gained with regard to TFL theory and also this study provides the new mechanism to advance TFL outcomes in the workplace. TFL can actually alter the strengths of the followers (Afsar et al., 201;Waldman et al., 2006). However, linking the importance of TFL behavior to employee's creative performance cannot be denied since it widens our knowledge of the potential of transformational leadership quality. In regard, the evidence from this study underlined the importance of supervisory TFL behavior in driving employee's creative performance in the workplace. The new model developed in this study validates the utility of creative efficacy in mediating the relationship between supervisory leadership style and subordinate's creative behaviour and also demonstrates the vital role of climate for creativity to enhance employee's creative performance behaviour in the workplace. In this regard, we believe that we have found a cutting-edge solution for creativity challenge in the workplace

This study so far has been very promising and the approach employed has the potential. Despite this, our work clearly has some limitations. First, the fact that the data analyzed in this study were collected in a country that suffers from financial vulnerabilities where some companies may lack support for creativity, we can suggest similar studies in developed economies to avoid the possibility of generalizability of the findings. Second, in this study, we used a cross-sectional research design in collecting data. Although, this design can be Susceptible to bias due to limited respondent answers. In this regard, we can suggest a longitudinal approach for future studies on the current topic which can provide a higher degree of confidence due to the large sample size. Third, this study examines the effect of TFL behavior on employee's creative performance 
behavior in the workplace. Although to enhance our understanding of the final outcome of such widely adopted leadership behavior, further studies may link transformational leadership quality to the final organizational outcomes such as innovation performance and financial performance.

\section{References}

Afsar, B., Badir, Y. F., Saeed, B. Bin, \& Hafeez, S. (2016). Transformational and transactional leadership and employee 's entrepreneurial behavior in knowledge-intensive industries. The International Journal of Human Resource Management, 28(2), 307-332. https://doi.org/10.1080/09585192.2016.1244893

Afsar, B., F. Badir, Y., \& Bin Saeed, B. (2014). Transformational leadership and innovative work behavior. Industrial Management \& Data Systems, 114(8), 1270-1300. https://doi.org/10.1108/IMDS-052014-0152

Aurelija Stelmokiene \& Aukse Endriulaitiene. (2015). Transformational leadership in the perception of subordinates Personality traits and social identification. Baltic Journal of Management, 30(1), 4468. https://doi.org/10.1108/BJM-05-2014-0084

Bandura, A. (1989). Social cognitive theory. In R. Vasta (Ed.), Annals of Child Development, 6, 1-60. Greenwich, CT: JAI Press.

Bandura, A. (1994). Self-Efficacy. Encyclopedia of Human Behavior, 4, 71-81. New York: Academic Press

Bang, H., \& Jr, T. G. R. (2017). Personal Accomplishment, Mentoring, and Creative Self-Efficacy as Predictors of Creative Work Involvement: The Moderating Role of Positive and Negative Affect. The Journal of Psychology, 151(2), 148-170. https://doi.org/10.1080/00223980.2016.1248808

Bass, B. M. (1990). From Transactional to Transformational Leadership: Learning to Share the Vision. Organizational Dynamics, 18(3), 19-32. https://doi.org/10.1016/0090-2616(90)90061-S

Bass, B. M. (2000). The Future of Leadership in Learning Organizations. Journal of Leadership Studies, 7(3), 18-40. https://doi.org/10.1177/107179190000700302

Bass, B. M., \& Avolio, B. J. (1990). Developing Transformational Leadership: 1992 and Beyond.Journal of European Industrial Training, 14(5). https://doi.org/10.1108/03090599010135122

Bass, B. M., Avolio, B. J., Jung, D. I., \& Berson, Y. (2003). Predicting unit performance by assessing transformational and transactional leadership. Journal of Applied Psychology, 88(2), 207-218. https://doi.org/10.1037/0021-9010.88.2.207

Bass, B. M., \& Steidlmeier, P. (1999). Ethics, character, and authentic transformational leadership behavior. The Leadership Quarterly, 10(2), 181-217. https://doi.org/10.1016/S1048-9843(99)00016-8

Beghetto, R. A. (2010). Creative Self-Efficacy : Correlates in Middle and Secondary Students Creative SelfEfficacy : Correlates in Middle and Secondary Students. Creativity Research Journal, 18(4), 447457.

Bruce Gashema \& Yongqiang Gao. (2018). Strengthening Managerial Innovation Behavior in the SMEs: The Role of CEO Transformational Innovation Culture. International Journal of Research in Business and Social Science, 7(3), 36-56.

Carless, S. A., Wearing, A. J., \& Mann, L. (2000). A short measure of transformational leadership ( GTL Scale)--- 7 Items. Journal of Business and Psychology, 14(3). https://doi.org/10.1023/A:1022991115523

Carol Yeh-Yun Lin and Feng-Chuan Liu. (2012). A cross-level analysis of organizational creativity climate and perceived innovation. European Journal of Innovation Management, 15(1), 55-76. https://doi.org/10.1108/14601061211192834 
Bruce Gashema / International Journal of Research in Business and Social Science, Vol 8 No 4, 2019 ISSN: 2147-4486

Castro, C. B., Mar, M., Periñan, V., \& Casillas, J. C. (2008). Transformational leadership and followers ' attitudes : the mediating role of psychological empowerment. The International Journal of Human Resource Management, 5192(10), 1842-1863. https://doi.org/10.1080/09585190802324601

Chen, I., \& Chen, I. (2016). Examining the linkage between creative self-efficacy and work engagement to experience. Baltic Journal of Management, 11(4), 516-534. https://doi.org/10.1108/BJM-04-20150107

Choi, S. B., Kim, K., Ullah, S. M. E., \& Kang, S. (2016). How transformational leadership facilitates the innovative behavior of Korean workers. Personnel Review, 45(3), 459-479. https://doi.org/10.1108/PR-03-2014-0058

Cooper, B. L., Clasen, P., Jalonen, D. E. S., Butler, M. C., \& Cooper, B. L. (2006). Creative performance on an in-basket exercise Effects of inoculation against extrinsic reward. Journal of Managerial Psychology, 14, 39-56. https://doi.org/10.1108/02683949910254747

Cronbach, L. J. (1951). Coefficient alpha and the internal structure of tests. Psychometrika, 16(3), 297-334. https://doi.org/10.1007/BF02310555

Darvishmotevali, M., Altinay, L., \& Vita, G. De. (2018). International Journal of Hospitality Management Emotional intelligence and creative performance: Looking through the lens of environmental uncertainty and cultural intelligence. International Journal of Hospitality Management, 73(January), 44-54. https://doi.org/10.1016/j.jijhm.2018.01.014

de Jong, J. P. J., \& Den Hartog, D. N. (2007). How leaders influence employees' innovative behavior. European Journal of Innovation Management, 10(1), 41-64. https://doi.org/10.1108/14601060710720546

Esch, E. Van, Wei, L. Q., \& Chiang, F. F. T. (2018). High-performance human resource practices and firm performance : the mediating role of employees ' competencies and the moderating role of climate for creativity. The International Journal of Human Resource Management, 5192, 0. https://doi.org/10.1080/09585192.2016.1206031

Fairchild, A. J., \& MacKinnon, D. P. (2009). A general model for testing mediation and moderation effects. Prevention Science, 10(2), 87-99. https://doi.org/10.1007/s11121-008-0109-6

Fornell, C., \& Larcker, D. F. (1981). Evaluating Structural Equation Models with Unobservable Variables and Measurement Error. Journal of Marketing Research, 18(1), 39-50. https://doi.org/10.2307/3151312

Francis J.Yammarino and Bernard M. Bass. (1990). transformational leadership and multiple levels of analysis. SAGE Social Science Collections, 43(10), 975-995.

Ghadi, M., Fernando, M., \& Caputi, P. (2010). Transformational leadership , workplace engagement and the mediating influence of meaningful work: Building a conceptual framework. In the Australian New Zealand Academy of Management Annual Conference,36(6), 1-15. https://doi.org/10.1108/LODJ10-2011-0110

Hair, J. F., Black, W. C., Babin, B. J., \& Anderson, R. E. (2010). Multivariate Data Analysis. Vectors. https://doi.org/10.1016/j.jpharm.2011.02.019

Hair, J. F., Sarstedt, M., Ringle, C. M., \& Mena, J. A. (2012). An assessment of the use of partial least squares structural equation modeling in marketing research. Journal of the Academy of Marketing Science, 40(3), 414-433. https://doi.org/10.1007/s11747-011-0261-6

Hassi, A. (2019). Empowering leadership and management innovation in the hospitality industry context The mediating role of climate for creativity. International Journal of Contemporary Hospitality Management. https://doi.org/10.1108/IJCHM-01-2018-0003

Hayes, A. F. (2009). Beyond Baron and Kenny: Statistical mediation analysis in the new millennium.Communication Monographs, 46(4), 408-420. https://doi.org/10.1080/03637750903310360 
Bruce Gashema / International Journal of Research in Business and Social Science,

Vol 8 No 4, 2019 ISSN: 2147-4486

Heffernan, M., Harney, B., Cafferkey, K., \& Dundon, T. (2016). Exploring the HRM-performance relationship : the role of creativity climate and strategy. Employee Relations, 38(3), 438-462. https://doi.org/10.1108/ER-06-2015-0110

Hou, S., \& Fan, H. (2011). Creative Self-Efficacy and Innovative Behavior in a Service Setting : Optimism as a Moderator. Journal of Creative Behavior, 45(4), 258-272.

Hsu, M. L. A., \& Chen, F. H. (2017). The Cross-Level Mediating Effect of Psychological Capital on the Organizational Innovation Climate-Employee Innovative Behavior Relationship. The Journal of Creative Behavior, 51(2), 128-139. https://doi.org/10.1002/jocb.90

Hu, L. T., \& Bentler, P. M. (1998). Fit indices in covariance structure modeling: Sensitivity to underparameterized model misspecification. Psychological Methods, 3(4), 424-453. https://doi.org/10.1037//1082-989x.3.4.424

Hunter, S. T., Bedell, K. E., Mumford, M. D., Hunter, S. T., Bedell, K. E., Mumford, M. D., ... Mumford, M. D. (2007). Climate for Creativity: A Quantitative Review Climate for Creativity : A Quantitative Review. Creativity Research Journal, 19(1), 69-90. https://doi.org/10.1080/10400410709336883

Jaiswal, N. K., \& Dhar, R. L. (2015). Transformational leadership, innovation climate, creative self-efficacy and employee creativity: A multilevel study. International Journal of Hospitality Management, 51, 30-41. https://doi.org/10.1016/j.ijhm.2015.07.002

James C. Anderson \& David W. Gerbing. (1988). Structural equation modeling in practice: a review and recommended two-step approach. Psychological Bulletin, 103(3), 411-423.

Janssen, O. (2000). Job demands, perceptions of effort-reward fairness and innovative work behavior. Journal of Occupational and Organizational Psychology, 73, 287-302. https://doi.org/10.1348/096317900167038

Janssen, O. (2004). How fairness perceptions make innovative behavior more or less stressful. Journal of Organizational Behavior, 215, 201-215. https://doi: 10.1002/job.238

Jun Song, J. W. G. (2017). Voice behavior and creative performance moderated by stressors. Journal of Managerial Psychology. https://doi.org/10.1108/JMP-03-2016-0078

Jung, D. I., Bass, B. M., \& Sosik, J. J. (1995). Bridging Leadership and Culture: A Theoretical Consideration of Transformational Leadership and Collectivistic Cultures. Journal of Leadership Studies, 2(4), 318. https://doi.org/10.1177/107179199500200402

Jung, D. I., Chow, C., \& Wu, A. (2003). The role of transformational leadership in enhancing organizational innovation: Hypotheses and some preliminary findings. Leadership Quarterly, 14, 525-544. https://doi.org/10.1016/S1048-9843(03)00050-X

Jyoti Aggarwal \& Venkat R. Krishnan. (2015). Impact of Transformational Leadership on Job Performance. SAGE Open, 38(4), 297-313. https://doi.org/10.1177/2158244015612518

Kang, J. H., Solomon, G. T., \& Choi, D. Y. (2015). CEOs' Leadership styles and managers' Innovative behavior: Investigation of intervening effects in an entrepreneurial context. Journal of Management Studies, 52(4), 531-554. https://doi.org/10.1111/joms.12125

Karatepe, O. M. (2016). Does job embeddedness mediate the effects of coworker and family support on creative performance? An empirical study in the hotel industry. Journal of Human Resources in Hospitality \& Tourism, 15(2), 119-132. https://doi.org/10.1080/15332845.2016.1084852

Khalili, A. (2016). Linking transformational leadership, creativity, innovation, and innovation-supportive climate. Management Decision, 54(9), 2277-2293. https://doi.org/10.1108/MD-03-2016-0196

Kock, N., \& Lynn, G. S. (2012). Lateral Collinearity and Misleading Results in Variance-Based SEM : An Illustration and Recommendations. Journal of the Association for Information Systems, 13(7), 546580 . 
Bruce Gashema / International Journal of Research in Business and Social Science,

Vol 8 No 4, 2019 ISSN: 2147-4486

Koustab Ghosh. (2015). Developing organizational creativity and innovation. Management Research Review, 38(11), 1126-1148. https://doi.org/10.1108/MRR-01-2014-0017

Li, C., Zhao, H., \& Begley, T. M. (2015). Transformational leadership dimensions and employee creativity in China: A cross-level analysis. Journal of Business Research, 68(6), 1149-1156. https://doi.org/10.1016/j.jbusres.2014.11.009

Mafabi, S., Munene, J. C., Ahiauzu, A., Mafabi, S., \& Munene, J. C. (2015). Creative climate and organizational resilience : the mediating role of innovation. International Journal of Organizational Analysis, 23(4), 564-587. https://doi.org/10.1108/IJOA-07-2012-0596

Mathieu, J. E., \& Taylor, S. R. (2006). Clarifying conditions and decision points for mediational type inferences in Organizational Behavior. Journal of Organizational Behavior, 27(8), 1031-1056. https://doi.org/10.1002/job.406

Organ, D. W., \& Kovovsky, M. (1989). Cognitive versus affective determinants of organizational citizenship behavior. Journal of Applied Psychology, 74(1), 157-164.

Peterson, S. J., Walumbwa, F. O., Byron, K., \& Myrowitz, J. (2009). CEO positive psychological traits, transformational leadership, and firm performance in high-technology start-up and established firms. Journal of Management, 35(2), 348-368. https://doi.org/10.1177/0149206307312512

Puente-díaz, R. (2016). Creative Self-Efficacy: An Exploration of Its Antecedents, Consequences, and Applied Implications. The Journal of Psychology, 150(2), 175-195. https://doi.org/10.1080/00223980.2015.1051498

Raja, M. W. (2012). Does Transformational Leadership Leads To Higher Employee Work Engagement . A Study of Pakistani Service Sector Firms. International Journal of Academic Research in Business and Social Sciences, 2(1), 160-166. retrieved from www.hrmars.com/journals

Richard R Bagozzi \& Youjae Yi. (1988). On the Evaluation of Structural Equation Models.. Journal of the Academy of Marketing Science, 16(1). 0744-094

Sarros, J. C., Cooper, B. K., \& Santora, J. C. (2008). Through Transformational Leadership and Organizational Culture. Journal of Leadership \& Organizational Studies, 15(2), 145-158. https://doi.org/10.1177/1548051808324100

Scott, S. G., \& Bruce, R. A. (1994). Determinants of Innovative Behavior: a Path Model of Individual Innovation in the Workplace. Academy of Management Journal, 37(3), 580-607. https://doi.org/10.2307/256701

Shah, R., \& Goldstein, S. M. (2006). Use of structural equation modeling in operations management research: Looking back and forward. Journal of Operations Management, 24(2), 148-169. https://doi.org/10.1016/j.jom.2005.05.001

Simmons, A. L., \& Sower, V. E. (2014). Leadership sagacity and its relationship with individual creative performance and innovation. European Journal of Innovation Management, 15(3), 298-309. https://doi.org/10.1108/14601061211243648

Slåtten, T. (2014). Determinants and effects of employee's creative self-efficacy on innovative activities. International Journal of Quality and Service Sciences, 6(4), 326-347. https://doi.org/10.1108/IJQSS-03-2013-0013

Slåtten, T., \& Mehmetoglu, M. (2015). The Effects of Transformational Leadership and Perceived Creativity on Innovation Behavior in the Hospitality Industry. Journal of Human Resources in Hospitality and Tourism, 14(2), 195-219. https://doi.org/10.1080/15332845.2014.955557

Sung, S. Y., Du, J., \& Choi, J. N. (2018). Cognitive pathways of team climate for creativity: Implications for member creativity and job performance. Human Performance, 31(4), 197-215. https://doi.org/10.1080/08959285.2018.1509342 
Swati Mittal and Rajib Lochan Dhar. (2015). Transformational leadership and employee creativity. Management Decision, 53(5), 894-910. https://doi.org/10.1108/MD-07-2014-0464. https://doi.org/10.1108/MD-07-2014-0464

Tharnpas Sattayaraksa, Sakun Boon-itt. (2016). CEO transformational leadership and the new product development process The mediating roles of organizational. Leadership \& Organization Development Journal, 37(6), 730-749. https://doi.org/10.1108/LODJ-10-2014-0197

Thundiyil, T. G., Chiaburu, D. S., Li, N., \& Wagner, D. T. (2016). Joint effects of creative self-efficacy , positive and negative affect on. Chinese Management Studies, 10(4), 726-745. https://doi.org/10.1108/CMS-06-2016-0126

Waldman, D. A., Siegel, D. S., \& Javidan, M. (2006). Components of CEO Transformational Leadership and Corporate Social Responsibility Components of CEO Transformational Leadership. Journal of Management Studies. https://doi.org/10.1111/j.1467-6486.2006.00642.x

Yasin Ghadi, M., Fernando, M., \& Caputi, P. (2012). Transformational leadership and work engagement. Leadership \& Organization Development Journal, 34(6), 532-550. https://doi.org/10.1108/LODJ10-2011-0110

Yström, A., Aspenberg, H., \& Kumlin, A. (2015). Exploring the creative climate in an open innovation arena Identifying challenges and possibilities. European Journal of Innovation Management, 18(1), 7085. https://doi.org/10.1108/EJIM-08-2013-0085

Zuraik, A., \& Kelly, L. (2018). The role of CEO transformational leadership and innovation climate in exploration and exploitation. European Journal of Innovation Management, 40(2), 412-432. https://doi.org/10.1108/EJIM-10-2017-0142 